\title{
HydroProg: a system for hydrologic forecasting in real time based on the multimodelling approach
}

Tomasz Niedzielski, Bartłomiej Miziński, Maciej Kryza, Paweł Netzel, Małgorzata Wieczorek, Marek Kasprzak, Piotr Migoń, Mariusz Szymanowski, Justyna Jeziorska, Matylda Witek

University of Wrockaw, Institute of Geography and Regional Development, Plac Uniwersytecki 1, 50-137 Wrocław, Poland, e-mail: tomasz.niedzielski@uni.wroc.pl

\section{Wiesław Kosek}

University of Agriculture in Kraków, Faculty of Environmental Engineering and Land Surveying, Aleja Mickiewicza 24/28, 30-059 Kraków, Poland

\begin{abstract}
The objective of this paper is to present the concept of a novel system, known as HydroProg, that aims to issue flood warnings in real time on the basis of numerous hydrological predictions computed using various models. The core infrastructure of the system is hosted by the University of Wrocław, Poland. A newly-established computational centre provides in real time, courtesy of the project Partners, various modelling groups, referred to as "project Participants", with hydrometeorological data. The project Participants, having downloaded the most recent observations, are requested to run their hydrologic models on their machines and to provide the HydroProg system with the most up-to-date prediction of riverflow. The system gathers individual forecasts derived by the Participants and processes them in order to compute the ensemble prediction based on multiple models, following the approach known as multimodelling. The system is implemented in $\mathrm{R}$ and, in order to attain the above-mentioned functionality, is equipped with numerous scripts that manipulate PostgreSQL- and MySQL-managed databases and control the data quality as well as the data processing flow. As a result, the Participants are provided with multivariate hydrometeorological time series with sparse outliers and without missing values, and they may use these data to run their models. The first strategic project Partner is the County Office in Kłodzko, Poland, owner of the Local System for Flood Monitoring in Kłodzko County. The experimental implementation of the HydroProg system in the Nysa Kłodzka river basin has been completed, and six hydrologic models are run by scientists or research groups from the University of Wrocław, Poland, who act as Participants. Herein, we shows a single prediction exercise which serves as an example of the HydroProg performance.
\end{abstract}

Keywords: hydrology, ensemble prediction, multimodelling, real time prognosis, Kłodzko County

Submitted 18 July 2014, revised 3 February 2015, accepted 4 February 2015

\section{Introduction}

There are numerous methods for calculating hydrologic predictions. The majority of them are based on modelling. Although these methods can be classified according to various criteria, there are three fundamental characteristics that make a distinction between the approaches relatively straightforward. Namely, the predictive models may be (1) physically-based or data-based, (2) deterministic and/or stochastic, (3) lumped and/or distributed. These classifications along with their broad understanding are provided by Beven (2001) in his textbook, but can also be found in multiple papers, for instance by Krzysztofowicz (2001) in the context of deterministic/stochastic modelling and by Zhang et al. (2005) in the context of lumped/distributed approaches.
The first criterion mentioned above is based on theoretical fundamentals of a modelling strategy. Physicallybased models utilise physical laws to quantitatively describe riverflow generation processes. Not uncommonly, they make use of differential equations to describe the complexity of processes acting within a given basin. There are two specific models of this kind widely known in Europe that, with multiple modifications, have been used for approximately two decades. The first one in known as Système Hydrologique Européen (SHE) model (Abbott et al. 1986), while the second one is abbreviated as TOPMODEL, after its full name "TOPography based hydrological MODEL" (Beven, Kirkby 1979; Beven 1997). However, it is more difficult to unequivocally indicate key databased models, also referred to as empirical ones, as they 
are based on a large number of data processing techniques. Indeed, data-based approaches are often called blackbox models as they empirically link inputs with outputs without much understanding of the governing processes that drive a given phenomenon. The data processing techniques in question are taken from statistics, time series theory, artificial neural networks, data mining, genetic programming and transfer functions analysis. The majority of them aim to detect spatial and/or temporal dependencies between hydrometeorological inputs, as presented for instance Savic et al. (1999), Maier and Dandy (2000), Dawson and Wilby (2001), Whigham and Crapper (2001), Babovic (2005), Niedzielski (2007, 2010, 2011), Özcelik and Baykan (2009).

The second criterion is closely related to the regularity or irregularity of data and the corresponding models. Hydrologic time series are usually composed of periodic or trend-like signals - which may be approximated by certain deterministic functions - and chaotic signals, the stochastic nature of which may reveal multiple characteristics ranging from full randomness to a stochastic dependence controlled by a given stochastic process. Deterministic models quantitatively describe the variability that may be approximated by a single solution, obtained analytically or numerically. In contrast, within stochastic approaches a probability distribution controls the temporal variability of the model outputs, and hence there are usually multiple solutions driven by particular characteristics of a given probability distribution. There are also a considerable number of experiments in hydrology that use deterministic and/or stochastic methods (e.g. Clarke 1973; Laurenson 1976; Lawrance, Kottegoda 1977; Yevjevich 1987; Koutsoyiannis et al. 2008).

The third criterion is associated with geographical space and generalisation. The most general models are lumped models that relate hydrologic variability to a given basin, without the analysis of internal changes within the catchment. In contrast, distributed models act in a spatial domain so that every point located within a basin, and the hydrologic processes occurring at this location, has its specific contribution to runoff generation. There are also semi-distributed models which reveal the features of the aforementioned two classes of approaches, i.e. for analysis, mapping into a univariate case is performed, and the results are subsequently mapped back into the distributed mode. For instance, the SHE model is distributed, TOPMODEL is semi-distributed, and the unit hydrograph is lumped.

The above introduction clearly shows that there are numerous hydrologic models, and they are conceptually unlike each other. If a reader superimposes on the given back- ground a problem of geographical scale, the complexity increases. Indeed, some of the approaches work globally, other models are suitable for regional-scale investigations, and the remaining ones are useful solely for local-scale hydrologic analyses. However, the modeller neither has access to a large number of models nor is trained practically to use so many different tools. Thus, the following question arises: "what is actually a recommended model for a given prediction exercise". It is difficult to unequivocally provide a reasonable answer, as different models may perform differently, and this depends on location, scale, time, and environmental conditions. The solution to the problem of combining various predictive models in hydrology can be sought in the concept of multimodelling, the method that produces an ensemble prediction by assigning weights to multiple prognoses computed by numerous, often unrelated, hydrologic models. As described in a recent paper by Cloke and Pappenberger (2009), ensemble prediction systems, abbreviated as EPS, consist of several schemes. In particular, multimodelling is indeed treated as the ensemble prediction technique, but it is also important to discriminate between multimodelling itself and an ensemble forecast based on multiple Monte Carlo simulations derived from a single rainfall-runoff model.

In order to practically build the EPS, the coordination of various activities is desired. In the case of multimodelling, such coordination needs to be particularly well planned. Indeed, the models selected for the purpose of a given exercise should automatically produce predictions at the same time steps. The prognoses should have the same lead times and sampling intervals. The computationally reliable procedures should be employed to ensure an appropriate combination of multiple individual forecasts, with the reliable weighting approach in place. The problem arises when numerous models are run by the various institutions that elaborated and implemented them. In such a situation, in order to set up the multimodelling experiment it is necessary to create a computational centre that automatically controls the flow of data and predictions and also generates final ensemble products in real time. In this context, it also worth mentioning the OpenMI (Open Modelling Interface) which is often used in hydrology-related systems (Castronova et al. 2013; Castronova, Goodall 2013; Bugaets 2014).

There are a number of ensemble prediction campaigns throughout the world. The most important example is the Hydrologic Ensemble Prediction EXperiment (HEPEX), co-ordinated by the National Oceanic and Atmospheric Administration (NOAA) in the USA and the Joint Research Centre (JRC) of the European Commission based in Italy (Franz et al. 2005; Schaake et al. 2006). The EXperi- 
mental Ensemble Forecast Service (XEFS) is also developed by NOAA. In addition, it is worth mentioning the European FLOODRELIEF project, in which Polish researchers are involved; it focuses on attempts to combine and integrate multiple hydrologic predictive solutions (Butts et al. 2006a, b, 2007). For Alpine areas there exists a dedicated ensemble system known as the Mesoscale Alpine Programme Demonstration of Probabilistic Hydrological and Atmospheric Simulation of flood Events in the Alpine region (MAP D-PHASE) (Zappa et al. 2008). Such efforts aim to support and enhance operational solutions to mitigate water-related hazards, an example of which is the Observing System Research and Predictability Experiment (THORPEX) led by the World Meteorological Organization (WMO) (Bougeault et al. 2010).

Although there are several operational multimodelling/ ensemble systems, the development of such solutions is still an ongoing challenge. Given the fact that there is no operational hydrologic EPS in Poland that works in real time and is available for citizens, the research project entitled "System supporting a comparison of hydrologic predictions", supported by the National Science Centre in Poland commenced, in December 2011. The system in question is named HydroProg, and its main objective is to build a professional infrastructure, consisting of both the computation centre and novel geoinformation solutions. The objective of this paper is to present the concept and infrastructure of HydroProg, and to explain the HydroProgbased outputs using a simple numerical exercise based on the first experimental implementation of the system for the Nysa Kłodzka river basin.

\section{Concept and infrastructure}

The HydroProg system is based on interactions between its three elements/groups: the Executive institution (also referred to as the institution), Project Partners (known as partners) and Project Participants (known as participants). Their roles are explicitly stated in the official Project Regulations (abbreviated as regulations), published online at the dedicated project webpage: www.hydro.uni. wroc.pl. The institution is the University of Wrocław, where the project is run and where the computational centre is set up. Partners are external institutes or offices that provide the institution with hydrometeorological data on the basis of a separate agreement, and later the institution provides each partner with a set of individual forecasts, an ensemble prediction and a link to the dedicated web service. Participants are institutes that compute hydrological forecasts using the data provided by the institution according to rules established by the Participation Contract,

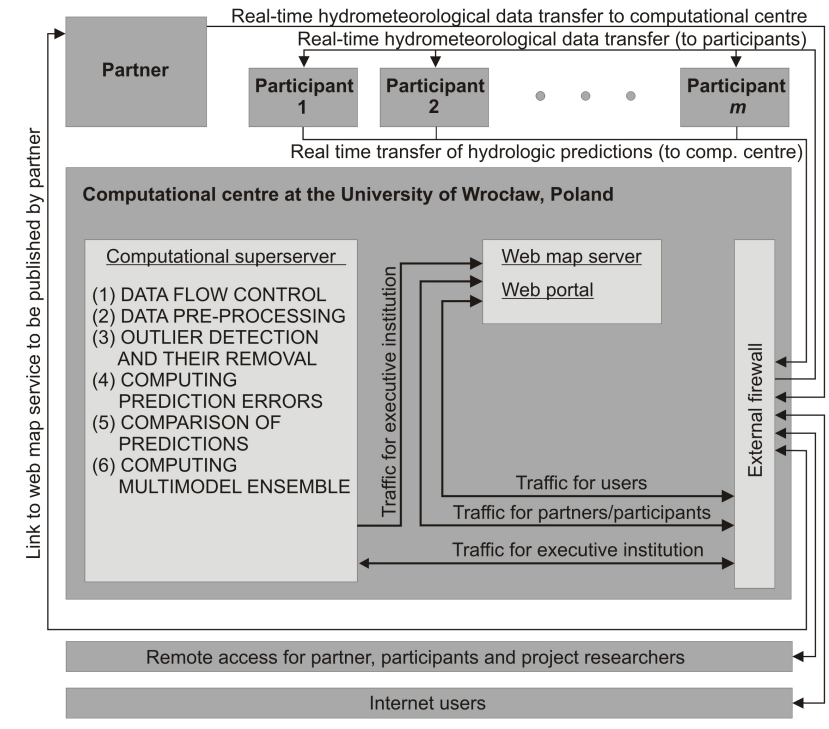

Fig. 1. Flow of data and predictions between Partner, Participants and Computational centre of HydroProg

known hereinafter as the contract. These roles, and data/ prediction flows, are presented in Fig. 1.

Hydrometeorological data are made available to participants courtesy of each partner (which in fact corresponds to a specific basin and experiment), both from historic archives and in real time. The data flow from a partner's repository to the computational centre is always preceded by the signing of a specific agreement between the institution and the partner. This addresses legal issues that concern data availability and their usage. Participants, a term which in fact corresponds to predictive models rather than specific institutes (one institute may use two independent models in the campaign), after signing bilateral contracts with the institution in order to obtain access to hydrometeorological data, compute in real time hydrologic forecasts for the selected gauges using the declared model(s). Thus, the agreements and contracts provide legal rules that control data flow. As a result, the database migrates to the computational centre, from which time series are served to participants who compute their prognoses and send them back to the computational centre. Having processed the submitted prediction in real time, the computational server publishes them, along with the ensemble forecasts based on the multimodelling approach, in the dedicated web service available on the Internet. Hence, citizens are provided with a hydrologic prediction service that is purely scientific, and it thus works along with a strict disclaimer of use. Such a legal framework allows the avoidance of conflicts with operational tasks carried out professionally by the Polish hydrological-meteorological survey. It is worth mentioning that Fig. 1 shows the system limited to one partner, denoted as Partner, but the same schemes, probably with slight modifications, may be used for other partners. 


\section{Methods}

A specific role of the computation centre should also be mentioned here. Apart from tasks dedicated to data flow, the computational centre performs multiple data processing assignments as juxtaposed in Fig. 2. The HydroProg system is developed in $\mathrm{R}$, which serves as a programming language and statistical environment. The entire system is formed by a set of engine files implemented in $\mathrm{R}$, the majority of which are interrelated. Along with engine files there is a structure of folders with various system files, for instance those for saving and updating logs as well as those for keeping configuration files. The system is elaborated to work in an intermittent way, i.e. each run is executed automatically at fixed time intervals from Linux Shell and after completing the job the system stops and later is called again.

As shown in Fig. 2, part (A) controls the start-up of the system and its subsequent runs at equal time step in real time. The aim of these procedures is also to handle errors, in the case of inappropriate parameters being entered or when the database reveals flaws. Details on both correct and incorrect runs of the systems are saved in logs, with a distinction between a so called "current log" (a mask that allows the discrimination between the first run and a subsequent run, and provides constant parameters for following runs) and "previous logs" that contain comprehensive information on HydroProg performance.

Part (B) consists of a database with four schemas, and attached to those schemas are numerous specific tasks that control the processes of filling the database with data. Raw data are stored in schema (B1). Archive data provided by a partner are read and saved in a table, while up-to-date records are attached to the table in real time. Such processes work in a way that handles errors driven by any breaks in hydrometeorological data availability or accessibility. Within the B1.2 segment a data control procedure was developed that checks if data are available in real time, and, if for some reason they are not available, the system keeps waiting and checking. When up-to-date observations occur again, the system checks the missing records and extends a table so that it contains all missing data caused by a break. However, such a table cannot serve the purpose of forecasting as (1) sampling times are not always the same (this may occur when there are delays between automatic observations in the field and storing the data in a partner's database) and (2) raw hydrometeorological data may consist of numerous artefacts. Therefore, the second schema (B2) comprises a table to be filled with good-quality hydrometeorological data saved for equal time steps, and hence at the same times every day. A few scripts have been

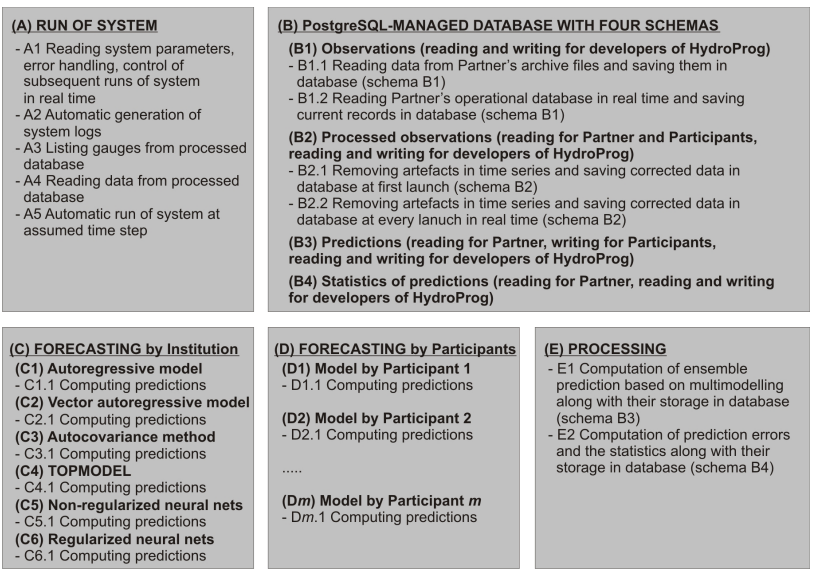

Fig. 2. Modules of HydroProg and their main tasks

elaborated to achieve this goal. The automatic process of removing outliers from hydrologic time series is based on the Rosner's test (McCuen 2003), and the removed suspicious data are replaced with the interpolated values. The hydrologic outliers, however, are sought in a multivariate way - a set of gauges located along the contributing rivers is considered and thus the Rosner's test is applied for interrelated sites. The meteorological data can be flagged following the procedure described by Shafer et al. (2000) and Estevez et al. (2011). The processed observations gathered in schema (B2) are made available for $\mathrm{m}+3$ participants. It should be noted that we generalise the definition of a participant and equate each participant with a single model. Following parts (C) and (D) in Fig. 2, we initially assumed three HydroProg models and m external models, all calculating the hydrologic predictions in real time for a given partner (which in fact corresponds to a given basin or a given experiment). The participants, after having calculated the prognoses, send the predictions via a dedicated network and save them within schema (B3) of the database. The HydroProg system processes these predictions in part (E), in which ensemble forecasts based on multimodelling are computed and full prediction error statistics are provided for each individual prognosis. The statistical characteristics of forecasts are stored within schema (B4).

Although pointwise hydrologic predictions are valuable, they should be complemented by spatial predictions of overbank flow. This is a complex task, however, the HydroProg initiative is being extended and such spatial prognoses, based on predictions for specific gauges, are now under development. Associated with this is the notion of verification of those spatial predictions of overbank flow. This will be attained by using the unmanned aerial vehicle (UAV) for photogrammetry and remote sensing, the use of which has been incorporated into the entire project (Witek et al. 2014).

As shown in Fig. 1, both individual and ensemble solutions are published on maps within the dedicated web map 
server. This concerns predictions and their errors, considered both pointwise and in a spatial domain.

\section{First experiment}

As mentioned above, our first strategic partner is the County Office in Kłodzko, Poland, the owner of the Local System for Flood Monitoring in Kłodzko County. The system is an example of well-designed infrastructure, and has had high reliability since April 2002. Kłodzko County is located in Kłodzko Valley. It includes a large mid-mountain abasement, and is vulnerable to damaging floods. Hence, there is a need for local strategies to counteract extreme hydrological events (Piepiora 2011). The main elements of the system are the following: a management centre, 22 automatic hydrologic gauging stations at which water level is measured every 15 minutes, and 18 automatic meteorological stations (with various sets of measured parameters) recording observations every 15 minutes. Among them, at four sites, both hydrologic and meteorological observations are made concurrently. The main river draining Kłodzko County is the Nysa Kłodzka River, a left tributary of the Odra River. The most significant tributaries of the Nysa Kłodzka River are: the Ścinawka River, the Bystrzyca Dusznicka River, the Bystrzyca Łomnicka River, the Wilczka River, the Biała Lądecka River and the Morawka River. Fig. 3 presents the river network of Kłodzko County along with locations of the aforementioned automatic hydrologic gauges and weather stations.

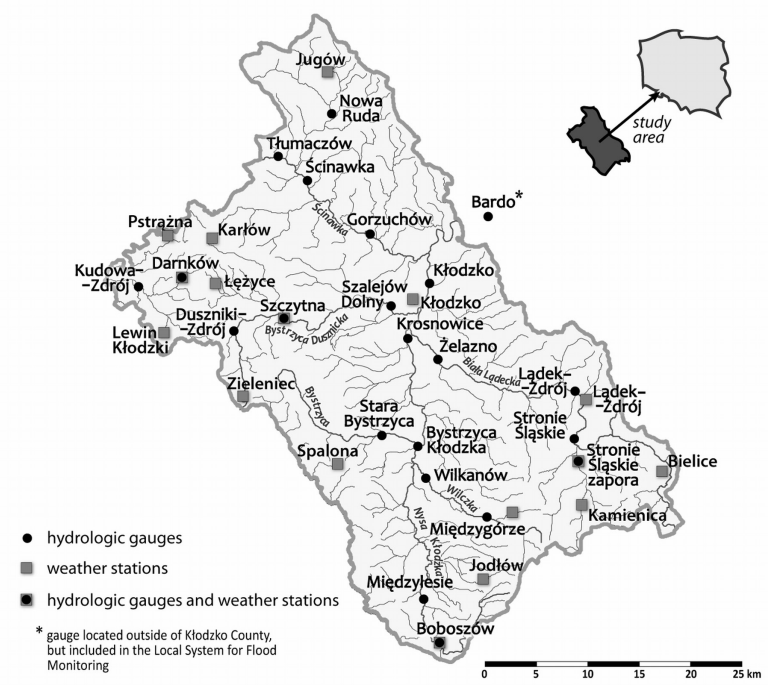

Fig. 3. River network in Kłodzko County and locations of automatic hydrologic gauges and weather stations of the Local System for Flood Monitoring of Kłodzko County

Following the official agreement between the University of Wrocław and the County Office in Kłodzko, the HydroProg researchers were provided with the archive hy- drometeorological data and received access to the operational database in real time. We successfully implemented all the functions needed to run the elements depicted in Fig. 2, and the experimental implementation for the upper Nysa Kłodzka river basin, referred to as HydroProgKłodzko, is now working in real time. To carry out realtime hydrologic modelling and forecasting, the upstream hydrological data are usually required. Based on this requirement, we selected a subset of gauges for which predictions are computed in real time. The selected 11 gauges, where HydroProg-based prognoses are computed, are the following:

- Międzylesie along along the Nysa Kłodzka River (explanatory information on riverflow from Boboszów),

- Bystrzyca Kłodzka along the Nysa Kłodzka River (explanatory information on riverflow from Boboszów, Międzylesie, Międzygórze, Wilkanów),

- Krosnowice along the Nysa Kłodzka River (explanatory information on riverflow from Boboszów, Międzylesie, Bystrzyca Kłodzka, Międzygórze, Wilkanów, Stara Bystrzyca),

- Kłodzko along the Nysa Kłodzka River (explanatory information on riverflow from Boboszów, Międzylesie, Bystrzyca Kłodzka, Krosnowice, Międzygórze, Wilkanów, Stara Bystrzyca, Stronie Śląskie zapora, Stronie Śląskie, Lądek-Zdrój, Żelazno, Duszniki-Zdrój, Szczytna, Szalejów Dolny),

- Bardo along the Nysa Kłodzka River (explanatory information on riverflow from Boboszów, Międzylesie, Bystrzyca Kłodzka, Krosnowice, Kłodzko, Międzygórze, Wilkanów, Stara Bystrzyca, Stronie Śląskie zapora, Stronie Śląskie, Lądek-Zdrój, Żelazno, Duszniki-Zdrój, Szczytna, Szalejów Dolny, Tłumaczów, Ścinawka Górna, Nowa Ruda, Gorzuchów),

- Lądek-Zdrój along the Biała Lądecka River (explanatory information on riverflow from Stronie Śląskie zapora, Stronie Śląskie),

- Żelazno along the Biała Lądecka River (explanatory information on riverflow from Stronie Śląskie zapora, Stronie Śląskie, Lądek-Zdrój),

- Szczytna along the Bystrzyca Dusznicka River (explanatory information on riverflow from DusznikiZdrój),

- Szalejów Dolny along the Bystrzyca Dusznicka River (explanatory information on riverflow from DusznikiZdrój, Szczytna),

- Ścinawka Górna along the Ścinawka River (explanatory information on riverflow from Tłumaczów, Nowa Ruda),

- Gorzuchów along the Ścinawka River (explanatory information on riverflow from Tłumaczów, Ścinawka Górna, Nowa Ruda). 
In the HydroProg-Kłodzko prototype the institution acts as participants. This means that the hydrologic models, which serve as ensemble members, are implemented and run in real time by researchers or research groups employed at the University of Wrocław, Poland. The HydroProg-Kłodzko prototype was launched in August 2013, with two hydrologic models working over a few months from its launch. By the end of 2014 we implemented six hydrologic models which provide experimental predictions of water levels. These models are: Vector AutoRegressive (VAR) model, AutoRegressive (AR) model, AutoCoVariance (ACV) method, TOPMODEL, non-regularized Artificial Neural Network AutoRegressive (ANNAR) model and regularized ANNAR. In addition to prognoses based on individual models, we calculate the multimodel ensemble forecast.

The VAR and AR prediction methods were previously examined by Niedzielski (2007), and the VAR approach was found to work well in cases of peak flows in the selected rivers of the Odra River basin. The VAR technique is multivariate and accounts for all spatio-temporal dependencies between hydrographs for dissimilar gauges located in the contributing catchment. In HydroProg-Kłodzko, to predict water levels at a given outlet, we consider explanatory information from upstream gauges in the contributing basin, with 15-minute updates of riverflow data, courtesy of the partner. However, the AR method is univariate, and hence only temporal dependencies are modelled. The ACV technique was elaborated by Kosek (2002) in the context of research in geodynamics, and its first application in hydrology is associated with HydroProg. The ACV method is univariate, but very often reveals a considerable potential in reconstructing high-frequency characteristics of predictions for big lead times. The TOPMODEL prediction is based on the combination of a frequently updated semi-distributed TOPMODEL (Beven, Kirkby 1979) and the Weather Research and Forecasting (WRF) mesoscale numerical meteorological model applied to forecast rainfall (Kryza et al. 2013). Both regularized and non-regularized ANNAR nets have one hidden layer, and are taught with the back propagation method, with the hyperbolic tangent activation function (Dawson, Wilby 2001). The two approaches are purely univariate and treat water level data as time series.

In order to present the concept of the HydroProg system, herein we present a simple case study based on the real-time performance of the HydroProg-Kłodzko prototype in forecasting the water level in Kłodzko during the episode on 20 December 2014. There was considerable rainfall in the contributing basin above the Kłodzko outlet, beginning on the 18 December 2014 and continuing into

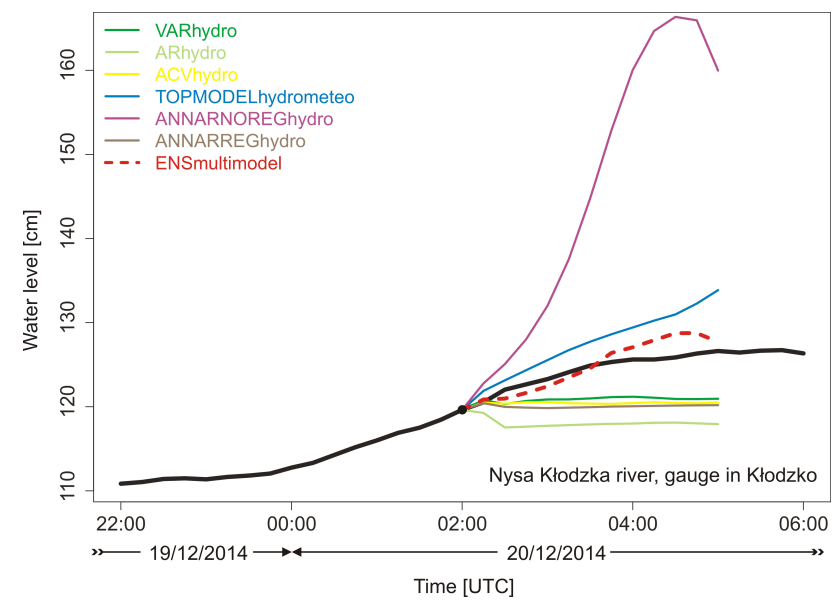

Fig. 4. Performance of the HydroProg-Kłodzko prototype in forecasting water level on 20/12/2014 at the gauge in Kłodzko; the multimodel ensemble is based on six ensemble members based on independent models

22 December 2014, with its maximum intensity on 19 December 2014. As a result, the water level in Kłodzko started to rise at about 23:30 UTC on 19 December 2014. The HydroProg-Kłodzko infrastructure kept calculating 3-hour predictions over the event, but for the purpose of this paper we have focused on the predictions calculated at 02:00 UTC into 05:00 UTC. Fig. 4 presents the performance of the six models mentioned above, and the multimodel ensemble prediction is also shown. It is apparent from Fig. 4 that prognoses based on all individual models considerably depart form the observed water level, however their mulimodel ensemble is very skilful in predicting the hydrograph. It is also worth noting that the exercise from 02:00 UTC into 05:00 UTC corresponds to predicting the peak of the hydrograph. The above-mentioned multimodel ensemble prognosis was also accurate in forecasting that peak of water level time series.

\section{Summary}

The The concept of the novel HydroProg system has been described, with a particular emphasis put on its infrastructure and formal issues. The system serves as a general tool which can be used for issuing warnings of hydrological hazards, such as peak flows. Embedded into HydroProg is the generator of the multimodel ensemble predictions. Thus, HydroProg can be applied to different river basins equipped with hydrometeorological gauging networks. The first implementation of the system, known as the HydroProg-Kłodzko prototype, is completed for the upper Nysa Kłodzka river basin, in which there exists the unique Local System for Flood Monitoring of Kłodzko County, SW Poland (Lokalny System Osłony Przeciwpowodziowej, LSOP). The performance of the HydroProg- 
Kłodzko prototype is presented on the basis of a case study which focuses on forecasting the rise of water level at the gauge in Kłodzko on 20/12/2014. Using six 3-hour predictions computed by dissimilar models, we confirmed that the HydroProg-based multimodel ensemble prognosis may skilfully forecast peak flows.

Acknowledgements. The research was financed and supported by the National Science Centre in Poland through grant no. 2011/01/D/ST10/04171 under the leadership of Dr hab. Tomasz Niedzielski, Professor at the University of Wrocław, Poland. We are also grateful to the authorities of the County Office in Kłodzko for providing us with hydrometeorological data collected at the gauges of the Local Flood Monitoring System and for giving us access to the dedicated real-time database. The HydroProg-Kłodzko prototype uses R, PostgreSQL and MySQL.

\section{Bibliography}

Abbott M.B., Bathurst J.C., Cunge J.A., O'Connell P.E., Rasmussen J., 1986, An introduction to the European Hydrological System - Système Hydrologique Européen, "SHE", 1: History and philosophy of a physically-based, distributed modelling system, Journal of Hydrology, 87 (1-2), 45-59, DOI: 10.1016/0022-1694(86)90114-9

Babovic V., 2005, Data mining in hydrology, Hydrological Processes, 19 (7), 1511-1515, DOI: 10.1002/hyp.5862

Beven K., 1997, TOPMODEL: A critique, Hydrological processes, 11 (9), 1069-1085, DOI: 10.1002/(SICI)10991085(199707)11:9<1069::AID-HYP545>3.0.CO;2-O

Beven K.J., 2001, Rainfall-Runoff Modelling, The Primer, Wiley, Chichester

Beven K.J., Kirkby M.J., 1979, A physically based, variable contributing area model of basin hydrology/Un modèle à base physique de zone d'appel variable de l'hydrologie du basin versant, Hydrological Sciences Bulletin, 24 (1), 43-69, DOI: 10.1080/02626667909491834

Bougeault P., Toth Z., Bishop C., Brown B., Burridge D., Chen D.H., Ebert B., Fuentes M., Hamill T.M., Mylne K., Nicolau J., Paccagnella T., Park Y.-Y., Parsons D., Raoult B., Schuster D., Dias P.S., Swinbank R., Takeuchi Y., Tennant W., Wilson L., Worley S., 2010, The THORPEX interactive grand global ensemble, Bulletin of the American Meteorological Society, 91 (8), 1059-1072, DOI: 10.1175/2010BAMS2853.1

Bugaets A.N., 2014, Using the OpenMI standard for developing integrated systems of hydrological modelling, Russian Meteorology and Hydrology, 39 (7), 498-506, DOI: 10.3103/ S1068373914070097

Butts M.B., Overgaard J., Dubicki A., Strońska K., Lewandowski A., Olszewski T., Kolerski T., 2006a, Intercomparison of distributed hydrological models for flood forecasting in the Odra River basin, Geophysical Research Abstracts, 8, 07250 Butts M.B., Falk A.K., Madsen H., Hartnack J., van Kalken T., Mulholland M., 2006b, Ensemble-based flood forecasting with real-time observations for data assimilation, Geophysical Research Abstracts, 8, 07519

Butts M., Dubicki A., Strońska K., Jørgensen G., Nalberczynski A., Lewandowski A., Van Kalken T., 2007, Flood forecasting for the upper and middle Odra River basin, [in:] Flood Risk Management in Europe, S. Begum et al. (eds.), Advances in Natural and Technological Hazards Research, 25, 353-384, DOI: 10.1007/978-1-4020-4200-3_19

Castronova A.M., Goodall J.L., Ercan M.B., 2013, Integrated modelling within a Hydrologic Information System: An OpenMI based approach, Environmental Modelling \& Software, 39, 263-273, DOI: 10.1016/j.envsoft.2012.02.011

Castronova A.M., Goodall J.L., 2013, Simulating watersheds using loosely integrated model components: Evaluation of computational scaling using OpenMI, Environmental Modelling \& Software, 39, 304-313, DOI: 10.1016/j.envsoft.2012.01.020

Clarke R.T., 1973, A review of some mathematical models used in hydrology, with observations on their calibration and use, Journal of Hydrology, 19 (5), 1-20, 10.1016/00221694(73)90089-9

Cloke H.L., Pappenberger F., 2009, Ensemble flood forecasting: A review, Journal of Hydrology, 375 (3-4), 613-626, DOI: 10.1016/j.jhydrol.2009.06.005

Dawson C.W., Wilby R.L., 2001, Hydrological modelling using artificial neural networks, Progress in Physical Geography, 25 (1), 80-108, DOI: 10.1177/030913330102500104

Estevez J., Gavilan P., Giraldez J.V., 2011, Guidelines on validation procedures for meteorological data from automatic weather stations, Journal of Hydrology, 402 (5), 144-154, DOI: 10.1016/j.jhydrol.2011.02.031

Franz K., Ajami N., Schaake J., Buizza R., 2005, Hydrologic ensemble prediction experiment focuses on reliable forecasts, Eos Transactions American Geophysical Union, 86 (25), 239, DOI: $10.1029 / 2005 \mathrm{EO} 250004$

Kosek W., 2002, Autocovariance prediction of complex-valued polar motion time series, Advances in Space Research, 30, 375-380

Koutsoyiannis D., Yao H., Georgakakos A., 2008, Medium-range flow prediction for the Nile: a comparison of stochastic and deterministic methods/Prévision du débit du Nil à moyen terme: une comparaison de méthodes stochastiques et determinists, Hydrological Sciences Journal, 53 (1), 142-164, DOI: 10.1623 /hysj.53.1.142

Kryza M., Werner M., Wałaszek K., Dore A.J., 2013, Application and evaluation of the WRF model for high-resolution forecasting of rainfall - a case study of SW Poland, Meteo- 
rologische Zeitschrift, 22 (5), 595-601, DOI: 10.1127/09412948/2013/0444

Krzysztofowicz R., 2001, The case for probabilistic forecasting in hydrology, Journal of Hydrology, 249 (1-4), 2-9, DOI: 10.1016/S0022-1694(01)00420-6

Laurenson E.M., 1976, Modeling of stochastic-deterministic hydrologic systems, Water Resources Research, 10 (5), 955961, DOI: 10.1029/WR010i005p00955

Lawrance A.J., Kottegoda N.T., 1977, Stochastic modelling of riverflow time series, Journal of the Royal Statistical Society. Series A (General), 140 (1), 1-47, DOI: 10.2307/2344516

Maier H.R., Dandy G.C., 2000, Neural networks for the prediction and forecasting of water resources variables: a review of modelling issues and applications, Environmental Modelling \& Software, 15 (1), 101-124, DOI: 10.1016/S13648152(99)00007-9

McCuen R.H., 2003, Modeling hydrologic change: statistical methods, Lewis Publishers, London, NY, Washington, DC

Niedzielski T., 2007, A data-based regional scale autoregressive rainfall-runoff model: a study from the Odra River, Stochastic Environmental Research and Risk Assessment, 21 (6), 649-664, DOI: 10.1007/s00477-006-0077-y

Niedzielski T., 2010, Empirical hydrologic predictions for Southwestern Poland and their relation to ENSO teleconnections, Artificial Satellites, 45 (1), 11-26, DOI: 10.2478/v10018010-0002-y

Niedzielski T., 2011, Is there any teleconnection between surface hydrology in Poland and El Niño/Southern Oscillation?, Pure and Applied Geophysics, 168 (5), 871-886, DOI: 10.1007/ s00024-010-0171-4

Özcelik C., Baykan O., 2009, An improved time series model for monthly stream flows, Stochastic Environmental Research and Risk Assessment, 23 (5), 587-601, DOI: 10.1007/ s00477-008-0244-4

Piepiora Z., 2011, Lokalna polityka przeciwdziałania skutkom katastrof naturalnych w powiecie kłodzkim, Prace Naukowe Uniwersytetu Ekonomicznego we Wrocławiu, 152, 378-394
Savic D.A., Walters G.A., Davidson J.W., 1999, A genetic programming approach to rainfall-runoff modelling, Water Resources Management, 13 (3), 219-231, DOI: 10.1023/A:1008132509589

Schaake J., Franz K., Bradley A., Buizza R., 2006, The Hydrologic Ensemble Prediction EXperiment (HEPEX), Hydrology and Earth System Sciences Discussions, 3, 3321-3332

Shafer M.A., Fiebrich C.A., Arndt D.S., Fredrickson S.E., Hughes T.W.,2000, Quality assurance procedures in the OklahomaMesonetwork, Journal of Atmospheric and Oceanic Technology, 17, 474-494, DOI: 10.1175/1520-0426(2000)017<0474:QA PITO $>2.0 . \mathrm{CO} ; 2$

Whigham P.A., Crapper P.F., 2001, Modelling rainfall-runoff using genetic programming, Mathematical and Computer Modelling, 33 (6-7), 707-721, DOI: 10.1016/S0895$7177(00) 00274-0$

Witek M., Jeziorska J., Niedzielski T., 2014, Experimental approach to verify prognoses of floods using the unmanned aerial vehicle, Meteorology Hydrology and Water Management - Research and Operational Applications, 2, 3-11

Yevjevich V., 1987, Stochastic models in hydrology, Stochastic Hydrology and Hydraulics, 1 (1), 17-36, DOI: 10.1007/ BF01543907

Zappa M., Rotach M.W., Arpagaus M., Dorninger M., Hegg C., Montani A., Ranzi R., Ament F., Germann U., Grossi G., Jaun S., Rossa A., Vogt S., Walser A., Wehrhan J., Wunram C., 2008, MAP D-PHASE: real-time demonstration of hydrological ensemble prediction systems, Atmospheric Science Letters, 9 (2), 80-87, DOI: 10.1002/asl.183

Zhang Q., Wang C., Shibasaki R., 2005, Distributed modeling of hydrologic system based on digital river basin, Environmental Informatics Archives, 3, 92-97 